УДК 658.1

\title{
Д. А. Блохина
}

Сибирский государственный университет науки и технологий имени академика

М.Ф. Решетнева, Красноярск, e-mail: bloxina91@yandex.ru

\section{Н. В. Кочкарева}

Сибирский государственный университет науки и технологий имени академика

М. Ф. Решетнева, Красноярск, e-mail: natalya.coshkareva@ya.ru

\section{Е. В. Замиралова}

Сибирский государственный университет науки и технологий имени академика

М. Ф. Решетнева, Красноярск, e-mail: zamiralova@mail.ru

\section{ПРИМЕНЕНИЕ ПРОЦЕССНОГО ПОДХОДА В ОРГАНИЗАЦИИ, ОКАЗЫВАЮЩЕЙ ФАРМАЦЕВТИЧЕСКИЕ УСЛУГИ}

Ключевые слова: фармацевтическое предприятие, система менеджмента качества, процессный подход, цепочка создания ценности, диаграмма потоков работ.

В статье раскрывается сущность процессного подхода к управлению качеством в организации, оказывающей фармацевтические услуги. Представлена модель процессов системы менеджмента качества в соответствии со стандартом ISO 9000. Рассмотрены бизнес-процессы для предоставления фармацевтических услуг. Подчеркивается важность эффективной и действенной реализации процессов, включенных в систему. Отмечается необходимость применения на практике сети процессов. Представлен порядок выполнения двух процессов в форме диаграммы потоков работ. Определены показатели результативности для оценки бизнес-процессов. Сделан вывод о роли процессного подхода в системе менеджмента качества и в деятельности фармацевтических предприятий.

\section{A. Blokhina}

Reshetnev Siberian State University of Science and Technology, Krasnoyarsk, e-mail: bloxina91@yandex.ru

\section{N. V. Koshkareva}

Reshetnev Siberian State University of Science and Technology, Krasnoyarsk, e-mail: natalya.coshkareva@ya.ru

\section{E. V. Zamiralova}

Reshetnev Siberian State University of Science and Technology, Krasnoyarsk, e-mail: zamiralova@mail.ru

\section{APPLICATION OF THE PROCESS APPROACH IN THE ORGANIZATION PROVIDING PHARMACEUTICAL SERVICES}

Keywords: pharmaceutical company, quality management system, lean manufacturing, process approach, value chain, work flow chart.

The article reveals the essence of the process approach to quality management in the organization providing pharmaceutical services. A model of the processes of a quality management system in accordance with ISO 9000 is presented. Business processes for the provision of pharmaceutical services are reviewed. The importance of effective and efficient implementation of the processes included in the system is emphasized. The need to put into practice a network of processes is noted. The order of two processes in the form of a workflow diagram is presented. Performance indicators for evaluating business processes are defined. The conclusion is drawn about the role of the process approach in the quality management system and in the activities of pharmaceutical enterprises.

\section{Введение}

Одним из основополагающих принципов менеджмента качества является процессный подход, основная сущность которого заключается в следующем: «последовательные и прогнозируемые результаты достигаются более эффективно и результативно, когда деятельность осознается и управляется как взаимосвязанные процессы, которые функционируют как согласованная система [1]». Каждая организация должна рассматриваться как комплекс уникальных взаимосвязанных процессов, которыми необходимо управлять результативно и с максимальным экономическим эффектом. Процессный подход позволяет оптимизировать систему управления 
организацией и ее результаты, исключая дублирование функций. Особое место процессного подхода и процессов определена в стандарте ГОСТ Р ИСО 9001-2015 п. 4.4 «Система менеджмента качества и ее процессы» $[2,3]$. Существующие исследования в области развития процессного подхода $[4,5,6]$ и его практического применения [7] подчеркивают значимость и особую роль данного принципа в системе менеджмента качества (далее - СМК) любой организации. Таким образом, проводимые нами исследования являются теоретически обоснованными и практически значимыми в рассматриваемой фармацевтической отрасли.

\section{Цель исследования}

Целью исследования является применение процессного подхода в организации, оказывающей фармацевтические услуги, на примере бизнес-процессов «Контроль готовых лекарственных форм» и «Оприходование готовых лекарственных форм».

\section{Материалы и методы исследования}

В качестве материалов для исследования использована информация об организации, оказывающей фармацевтические услуги, её СМК, данные о выполняемых операциях (процессах). При сборе, обработке и анализе материалов применялись следующие методы научного исследования: изучение и обобщение информации из научной литературы, анализ, графический.

\section{Результаты исследования и их обсуждение}

Известно [1], что процесс представляет совокупность связанных и взаимодействующих действий, которые преобразуют входные данные в выходные и создают ценность для потребителя. Основной целью любого процесса является генерация ценности, которая будет оцениваться заказчиком. Ценность, созданная в результате деятельности, воспринимается потребителем, соотносится с его ожиданиями и выявляет степень его удовлетворенности.

В работе [7] нами был применен процессный подход на примере одной из организаций в следующей последовательности: построение цепочки создания ценности; классификация и выделение процессов для построения сети процес- сов; декомпозиция одного из бизнес-процессов; определение порядка выполнения выбранного процесса; определение показателей для оценки результативности выбранного процесса. В настоящей работе указанная последовательность была дополнена и апробирована на организации, оказывающей фармацевтические услуги, и включила в себя:

1) построение цепочки создания ценности для процесса реализации готовых лекарственных форм;

2) выделение бизнес-процессов, обеспечивающих процессов и процессов менеджмента и построение их сети в схематическом виде с учетом требований стандарта ГОСТ Р ИСО 9001-2015 [2, 3];

3) построение организационной структуры организации, оказывающей фармацевтические услуги, ориентированной на процессы;

4) построение матрицы ответственности за бизнес-процессы и обеспечивающие процессы;

5) документирование в форме регламента процесса (представлена структура документа).

Суть цепочки создания ценности в том, что полный цикл бизнес-процесса охватывает обеспечение сырьем, материалами, информационным и документационным потоком, создающий ценность для конечного потребителя. Визуализация потоков работ также облегчает общее представление процессов. Цепочка создания для процесса реализации готовых лекарственных форм представлена на рис. 1, где ГЛФ - готовые лекарственные формы.

На основании рис. 1 был составлен реестр процессов первого уровня, определена их классификация (процессы менеджмента, бизнес-процессы, обеспечивающие процессы) и построена сеть процессов СМК организации, оказывающей фармацевтические услуги. Стандарты ISO серии 9000 [2, 3] требуют выделять бизнес-процессы на всех уровнях иерархии и организовать их управление. В качестве примера в работе рассмотрены бизнес-процессы по оказанию фармацевтической услуги одной из аптек, которая входит в аптечную сеть (рис. 2). В осуществлении данных процессов задействованы: владелец процесса на уровне высшего руководства (заведующий аптекой) и нижний уровень уровень исполнителей (фармацевты). 


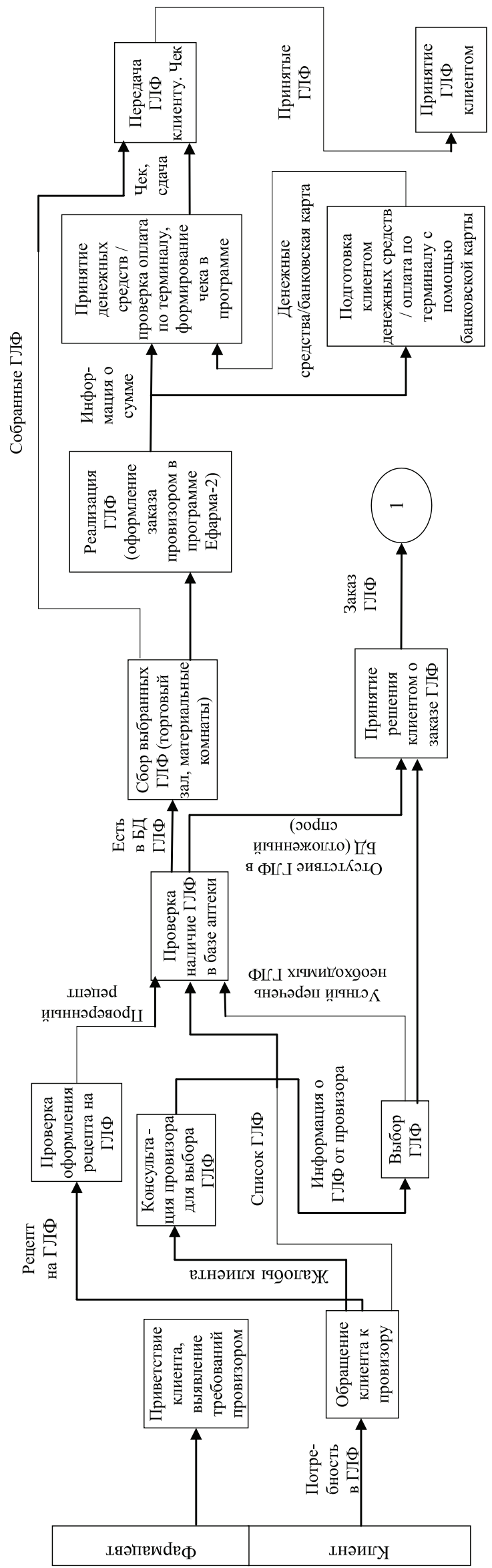

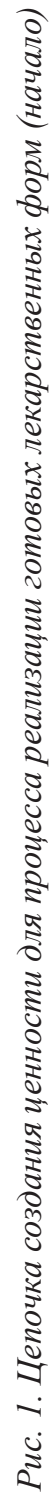




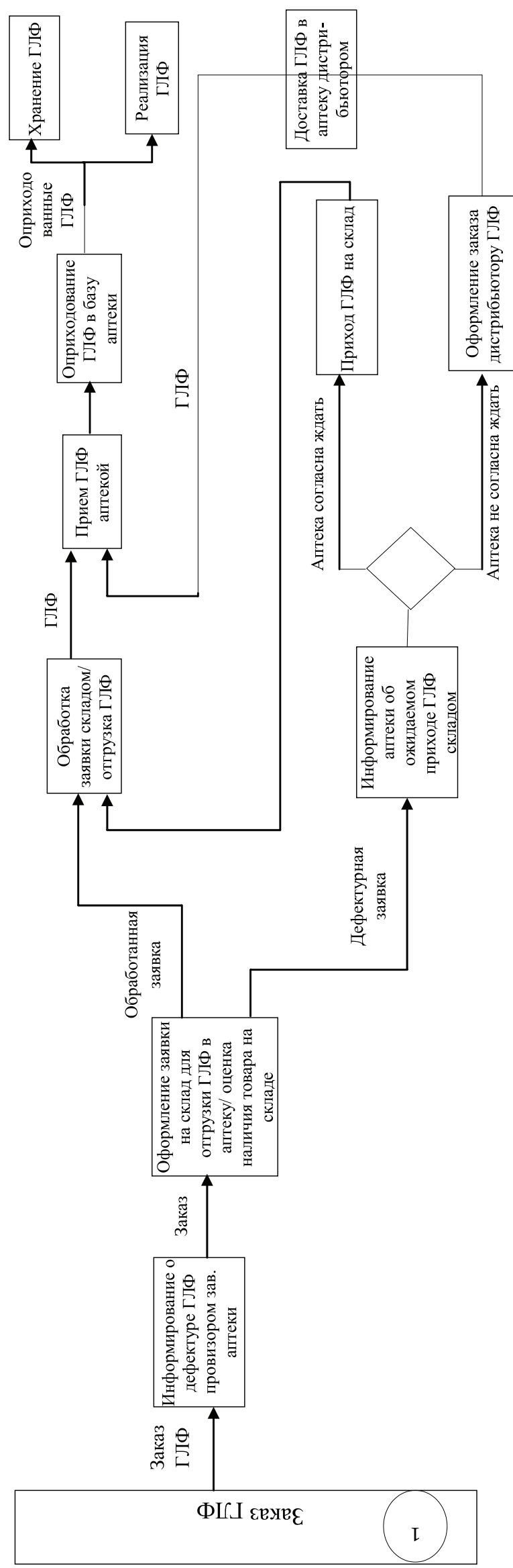

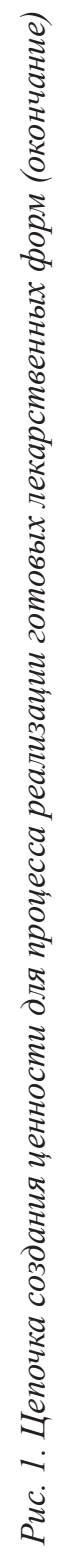




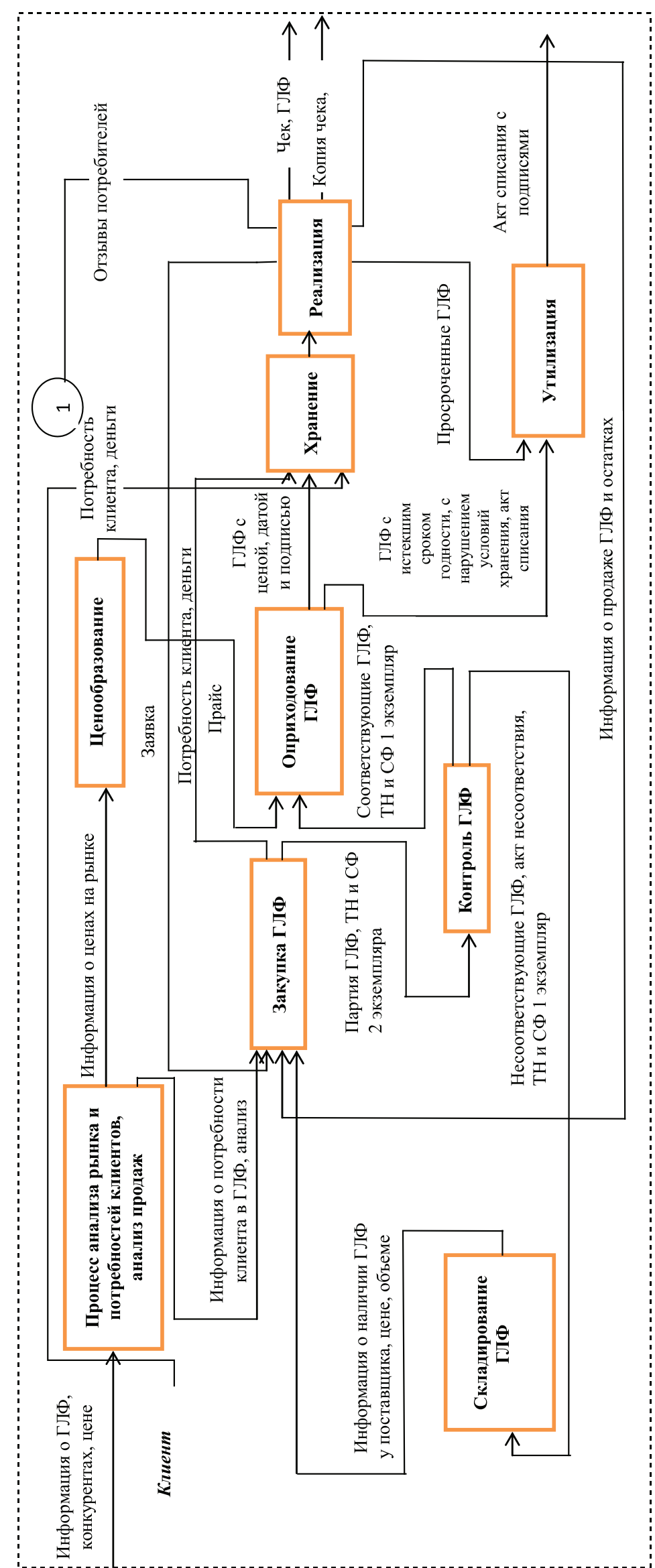

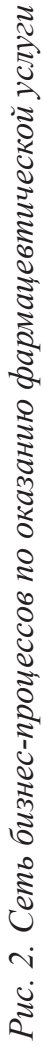


Представленная модель процессов (рис. 2) показывает истинную процедуру протекания процессов в аптеке, одинаково понятна для всех участников процессов, позволяет увидеть движение документов и товарных ценностей в аптеке, позволяет определить наиболее значимые ресурсы для предприятия и степень их использования. Также, данная сеть упрощает проведение аудита для выявления необходимых изменений в деятельности предприятия для приведения ее в соответствии с требованиями международных стандартов ИСО серии 3001. Любой процесс в организации должен быть продуктивным. Результатом является выполнение требований клиента, получение средств, обученный и мотивированный персонал, положительный имидж и конкурентоспособность. Результаты деятельности важно измерять и улучшать.

На основании рис. 1 и 2 была скорректирована организационная структура организации, оказывающей фармацевтические услуги, с учетом ориентации на процессы. И далее построена матрица распределения ответственности, которая показала, что значительная часть ответственности распределена неравномерно, в основном сосредоточена на заведующей аптекой, и не делегирована другим участникам процесса. Были даны рекомендации по передаче полномочий другим ответственным лицам, освобождение заведующей аптекой для управления и развития организации.

Согласно новой версии стандарта ИСО 9001 [2, 3] документирование не является обязательным, введено понятие документированной информации, и организация вправе определить целесообразность документирования своих процессов. В качестве рекомендаций для документирования бизнес-процессов нами был предложен регламент процесca, включающий 9 разделов:

1. Общие положения.

2. Общее описание процесса.

3. Результаты процесса и их потребители.

4. Входы процесса и их поставщики.

5. Графическая схема процесса.

6. Описание операций процесса.

7. Цели и показатели процесса.

8. Управление документами процесса.

9. Формы документов.
Подробнее нами рассмотрены два бизнес-процесса - «Контроль ГЛФ» и «Оприходование ГЛФ», так как они обеспечивают высокое качество лекарственных средств, поступающих в аптеку. Данные процессы подвергают проверке не только лекарственные средства, но и весь пакет сопроводительных документов - накладных (с обязательным указанием наименования, дозирование, лекарственной формы, номер серии, количества, названия производителя), сертификатов качества производителей, данных о регистрационном статусе лекарственного средств. Также, благодаря данным процессам, предприятие сразу изымает из оборота наличие некачественных и фальсифицированных серий лекарственных средств в соответствии с информацией территориальной инспекции. Для данных процессов разработан регламент с целью формирования единых правил и требований к выполнению процессов, установления ответственности за результат процессов и унификации/стандартизации документооборота.

На рис. 3 представлен порядок выполнения двух процессов в форме диаграммы потоков работ. Обозначения и сокращения: ГЛФ - готовые лекарственные формы; ТН - товарная накладная; СФ - счет-фактура.

Для данных процессов в аптеке установлены показатели (таблица), которые подвергаются мониторингу для обеспечения уверенности в том, что эти процессы осуществляются в соответствии с тем, как это было запланировано; определены возможные риски процессов и мероприятия, направленные на снижение рисков. Периодичность измерения ГЛФ - при каждом поступлении. Ответственный за измерение / сбор / расчет показателя - Заведующий аптекой.

Проанализировав данные о бизнеспроцессах «Контроль ГЛФ» и «Оприходование ГЛФ», выявлено, что в аптеке необходимо ввести ещё одну рабочую единицу - заведующего отделом ГЛФ, для того, чтобы входной контроль и оприходование были учтены сразу после заполнения журналов поставки в этот же день. 


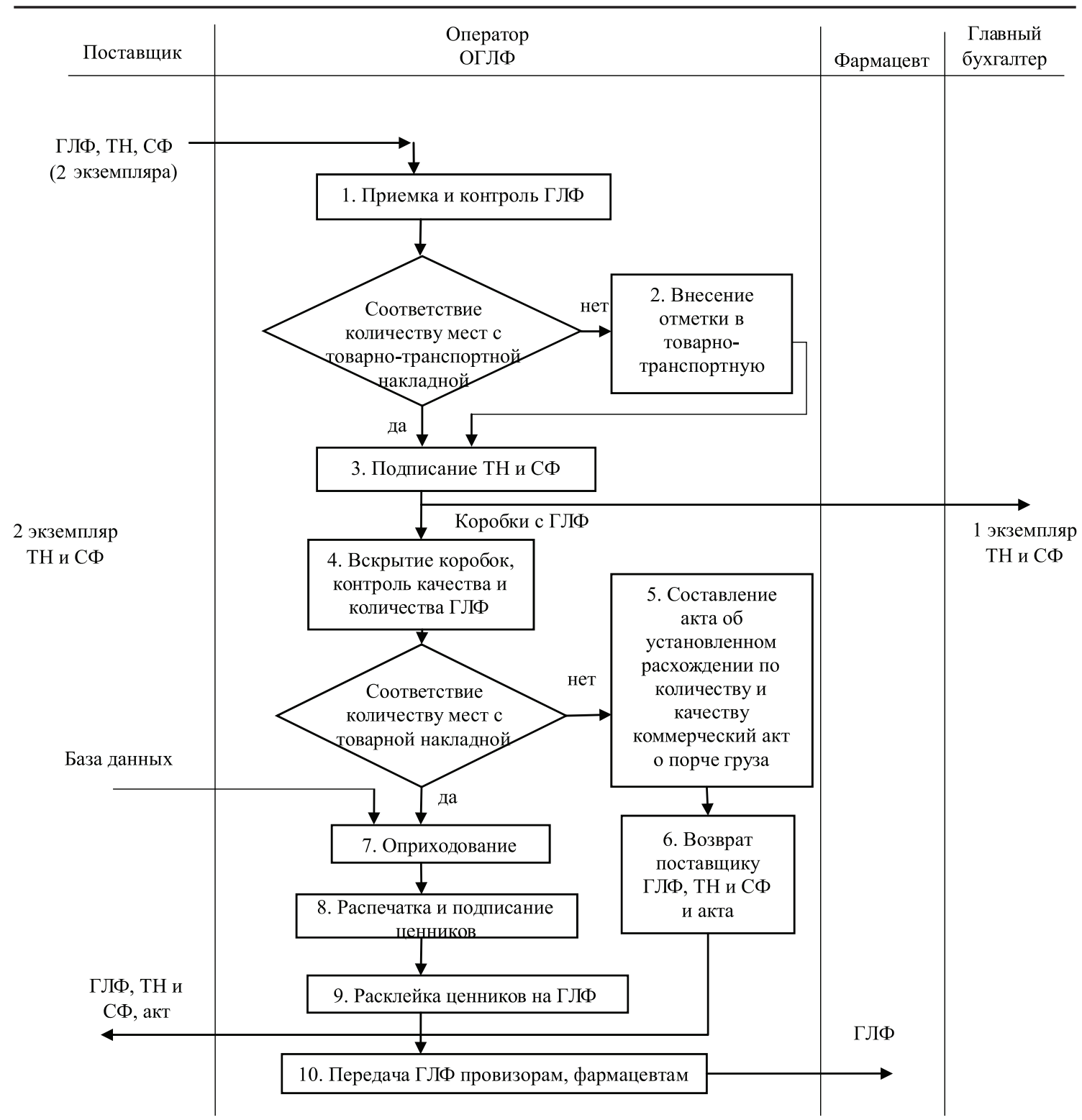

Рис. 3. Диаграмма потоков работ проиессов «Контроль и оприходование ГЛФ»

СМК, в том числе и процессный подход в аптеке, направлены на обеспечение населения качественными, эффективными и безопасными лекарственными препаратами, и обеспечивают: своевременное и качественное формирование аптечного ассортимента; обеспечение системы закупок, предотвращающей распространение фальсифицированных, недоброкачественных, контрафактных товаров аптечного ассортимента; оснащение помещений оборудованием, обеспечивающим надлежащее обращение товаров аптечного ассортимента; организацию контроля не попадания в аптечную сеть фальсифицированных, недоброкачественных, контрафактных товаров аптечного ассортимента; соблюдение надлежащей практики хранения и перевозки лекарственных препаратов; соблюдение правил отпуска лекарственных препаратов; соблюдение лицензионных и санитарных требований.

Как и любая теория, теория процессного подхода имеет свои недостатки и преимущества.

Говоря о преимуществах процессного подхода при управлении качеством, необходимо выделить следующие [6]: позволяет обратить внимание на важные виды деятельности организации, в которые включены все подразделения и отделы; усиливается взаимосвязь деятельности подразделений и отделов; повышается 


\begin{tabular}{|c|c|c|c|}
\hline \multicolumn{4}{|c|}{ Показатели процесса «Контроль и оприходование ГЛФ» } \\
\hline Показатель & $\begin{array}{l}\text { Единица из- } \\
\text { мерения }\end{array}$ & $\begin{array}{c}\text { Описание метода сбора } \\
\text { и расчета показателя }\end{array}$ & Результат контроля \\
\hline $\begin{array}{l}\text { Оценка соответствия } \\
\text { ГЛФ по качеству и ко- } \\
\text { личеству при приемке } \\
\end{array}$ & $\begin{array}{l}\text { Отсутствие от- } \\
\text { клонений }\end{array}$ & $\begin{array}{l}\text { Осмотр ГЛФ и фиксиро- } \\
\text { вание о приемке в жур- } \\
\text { нале поставки ГЛФ } \\
\end{array}$ & Журнал поставки ГЛФ \\
\hline $\begin{array}{l}\text { Оформление } \\
\text { результатов при } \\
\text { соответствии / } \\
\text { несоответствии при } \\
\text { приемке ГЛФ }\end{array}$ & $\begin{array}{l}\text { Количество ли- } \\
\text { стов ТН и акта } \\
\text { об установлен- } \\
\text { ном расхожде- } \\
\text { нии по качеству } \\
\text { и количеству }\end{array}$ & $\begin{array}{l}\text { Согласно Инструкции } \\
\text { «Порядок приемки, } \\
\text { хранения и перемеще- } \\
\text { ния товара (ГЛФ)» }\end{array}$ & $\begin{array}{l}\text { База данных (Е-форма), акт } \\
\text { об установленном расхожде- } \\
\text { нии по качеству и количеству, } \\
\text { коммерческий акт о поврежде- } \\
\text { нии (порче) груза, претензия } \\
\text { поставщику, уведомление по- } \\
\text { ставщику о расхождении цен } \\
\end{array}$ \\
\hline $\begin{array}{l}\text { Время выполнения } \\
\text { приемки ГЛФ }\end{array}$ & День & $\begin{array}{l}\text { Согласно Инструкции } \\
\text { «Порядок приемки, } \\
\text { хранения и перемеще- } \\
\text { ния товара (ГЛФ)» }\end{array}$ & Журнал приемки ГЛФ \\
\hline
\end{tabular}

вовлеченность персонала; позволяет рассматривать деятельность с точки зрения добавленной ценности, так как входы преобразуются в выходы; возникает четкое понимание, какие результаты будут итогом деятельности и кто заинтересован в их получении; повышается направленность на выполнение требований потребителя. Недостатки в данном подходе имеют немаловажную роль, основные из них: сложность реализации (документирование и согласование процессов, разработка управленческих регламентов и стандартов, преодоление стереотипов командного, функционального управления); потребность специального обучения и освоения навыков.

\section{Заключение}

При процессном подходе вся деятельность аптеки разбивается на взаимосвязанные процессы. Прежде всего, процессный подход в аптеке помогает понять, как устроена работа, и позволяет лучше управлять её выполнением: оптимизиро- вать структурное построение организации; предвидеть и минимизировать потери (материальные, трудовые, финансовые); давать стоимостную оценку каждому из бизнес-процессов и всей совокупности бизнес-процессов; производить стоимостное моделирование сетей бизнес-процессов, управляя ценовой конкурентоспособностью организации; позволяет регламентировать работу, т. е. зафиксировать порядок ее исполнения; проанализировать, как аптека взаимодействует с покупателями, поставщиками, как организована деятельность на каждом рабочем месте.

В работе показано практическое применение процессного подхода на примере организации, оказывающей фармацевтические услуги, представлены цепочка создания ценности и сеть бизнес-процессов. Приведены отдельные положения регламента процесса. Представленный материал может быть использован другими аптеками с целью совершенствования совей деятельности и повышения управляемости процессов и СМК в целом.

Библиографический список

1. ГОСТ Р ИСО 9000-2015 Системы менеджмента качества. Основные положения и словарь. М.: Стандартинформ, 2015. $53 \mathrm{c.}$

2. ГОСТ Р ИСО 9001-2015 Системы менеджмента качества. Требования. М.: Стандартинформ, 2015.24 с.

3. ГОСТ Р 57189-2016/ISO/TS 9002:2016 Системы менеджмента качества. Руководство по применению ИСО 9001:2015. М.: Стандартинформ, 2015. 32 с.

4. Кошкарева, Н.В. Проектирование процессов: курс лекций для студентов направлений 27.04.02 «Управление качеством» всех форм обучения / Н.В. Кошкарева; Сиб. гос. ун-т науки и технологий. Красноярск, 2017. 99 с.

5. Система менеджмента качества организации: коллективная монография / под общ. ред. В.В. Левшиной. Новосибирск: изд. АСН «СибАК», 2018. 208 с.

6. Репин В.В., Елиферов В.Г. Процессный подход к управлению: Моделирование бизнес-процессов. М.: РИА «Стандарты и качество», 2004. 90 с.

7. Опыт применения процессного подхода в организации строительной отрасли / А.А. Фадина, Е.В. Замираловва // Актуальные проблемы экономики и управления в XXI веке: сб. науч. ста-тей. Ч. 2; Сиб. гос. индустр. ун-т. Новокузнецк, 2017. С. 42-48. 